\title{
A Review of the Children's Health Insurance Program Reauthorization Act (Chipra) and its Implementation in Louisiana, USA
}

\author{
Alexandra Adetutu Oseni ${ }^{1}$ and Titilope Akinsanmi ${ }^{2}$ \\ Southern University and A \& M College, Public Policy Dept. Baton Rouge, Louisiana \\ 1. adetutuo2002@gmail.com \\ Southern University and A \& M College, Public Policy Dept. Baton Rouge, Louisiana
} 2. titilopeakinsanmi@yahoo.co.uk

\begin{abstract}
The study reviews the Children's Health Insurance Program Reauthorization Act (CHIPRA) and its implementation in Louisiana, USA. The Act was enacted at the Federal level to assist the various States to provide health care coverage to the eligible children only, through either Medicaid or the CHIP programs. The CHIPRA through the CHIP was managed by states, according to the federal requirements, set rules and measures. At the same time, the CHIP program through the CHIPRA was both financed by the various states and the federal government to ensure a healthy growth among America's children. The Act (CHIPRA) paid little or no consideration to the great number of the non-immigrant and immigrant children in the United States of America, thereby exposing the less disadvantaged immigrants' and non-immigrant children at the school going age to high risk of infectious diseases whenever there is an outbreak. Meanwhile, from the policy review perspective the Act and its associated programs are likely to be failed in terms of recurrent cost of treating diseases and fighting eradication in the near future. Perhaps, this is true because it has been observed over the years that the entire non-immigrant and immigrant children of school-going-age population group mingled-up with the native American Children in classrooms, playing grounds and many other recreational centers for fun, which makes it impossible to eradicate any outbreak of infectious diseases. For the purposes of the review of the CHIPRA and CHIP program, the study adopted Chi-Square analytical techniques, and also utilizes primary sources of data to evaluate or review CHIPRA from the perception of the American residents. As a result the study found out that it is very difficult for CHIP to embark on disease eradication among all school going age children (or infants) when an outbreak occurred. Additionally, the study underscored that majority of the respondents were of the view that CHIP through the CHIPRA is seen as a high-cost intensive program-which is also likely to be inefficient in operation based on it purposes of establishment (i.e. disease eradication or controls outbreak among children). Therefore, this current study highly recommends that at the State-level, legislativebodies, policymakers and governors should re-package the CHIP and also review the CHIPRA to cover all the school going age children at the state-level in order to protect the children from any outbreak of disease for eradication to be possible.
\end{abstract}

KEYWORDS: Medicaid, Health Insurance, CHIPRA, Equality, CHIP, and Epidemiology

DOI: $10.7176 /$ PPAR/10-2-07

Publication date: February $29^{\text {th }} 2020$

\section{INTRODUCTION}

In February 2009, President Barack Obama signed the Children's Health Insurance Program Reauthorization Act (CHIPRA). CHIPRA reauthorized the children's Health Insurance Program (CHIP) through federal fiscal year (FY) 2013. CHIPRA provided an additional \$ 35 billion in Federal funds that enabled States to maintain their current CHIP programs and also increased enrollment in Medicaid and CHIP. CHIPRA in its implementation has provided funding for grants for fiscal years 2009-2013, expressly for the purpose of funding activities that identified and enrolled eligible but uninsured children in coverage with a particular focus on those that were the most difficult to reach. The program started in September 2009 and was completed in December 2012. The implementation of the CHIPRA leads to the establishment of the Child Health Insurance Program (CHIP) at the state-level. The CHIPRA implementation through the CHIP program provided low-cost health insurance premium coverage to children in the low-income families. The CHIP has been partially effective (or ineffective) in controlling an outbreak of disease to the citizens among children of school going age due to its policy initiatives. Also, it has been observed by many researchers that the CHIP through CHIPRA has over the decades been disproportionately implemented the child health insurance policy across the different states in the United 
States of America, including Louisiana. The reason had been that some states CHIP through CHIPRA covers some pregnant women who carry an expected unborn American citizen; a case in point is the Louisiana Medicaid policy for pregnant women. The implementation of CHIPRA as a form of health insurance package in the United States of America, mandate every state to provide CHIP coverage, and also operates directly with the Medicaid program available to each state.

It is an important and an undeniable fact to note that health is a precious commodity that everyone desires for him/herself and their family. Most especially, parents desire and delight in the health of their children. In the epidemiological standpoint, children, old or aged group, pregnant women, and or women consume more health care or need more health care attention in a given society (Adu-Frimpong, 2016; Adu-Frimpong, 2019). They are more susceptible to an outbreak of disease and are likely to be infected when they are not covered or protected with insurance coverage (Adu-Frimpong, 2016; Adu-Frimpong, 2019). Meanwhile, health care costs as well as fee for service are very expensive or high throughout the United States of America (Adu-Frimpong, 2016). Since by default, majority of any given population are risk averse they tend to look for health insurance coverage to take care of future risk or sickness- that is, people do not know how much health care expenditure or cost to spend when they are not-well or are exposed to risk (Adu Frimpong, 2016; Grossman, 2000). According to Adu-Frimpong (2016) health insurance is in high demand due to the nature of the risk type of the majority (i.e. risk averse), as a result of the high demand in health care in USA, the cost has gone-up making it very expensive when one is uninsured. Subsequently, the Federal government came out with CHIPRA to help protect children. The CHIPRA emerged to provide low-cost health coverage for eligible children in USA. According to Dorsey (2016) the CHIP through CHIPRA provides health coverage for children so that they can get routine check-ups, immunizations and dental care to keep them healthy. This program (CHIP) work hand-in-hand with Medicaid, but all the afore-mentioned benefits derived from CHIPRA is only available for native children (Americans) alone.

Regarding the review purposes, readers are to learn that Medicaid program which works in tandem with the CHIPRA administers several programs that provide various health care coverage services at a low cost to children and families who meet certain eligibility qualifications. The section of eligibility in the CHIPRA excused some significant number of sensitive children in the United State from the insurance policy which therefore calls for policy or Act review and revision. Very importantly, given the numerous health insurance packages available to the health care market, the most affordable packages are ascribed to the Government Health Insurance packages as compared to the private health insurance- which can be easily obtained and enrolled at a potentially lower cost through subsidies or available specialized lower premiums based on what a person qualify for coverage. Interestingly, Dorsey (2016) since the purpose of the Government health insurance package is not for universal coverage, whereby not everyone qualifies for such premium or coverage, mostly because a household makes too much money or is not a citizen or permanent resident. If the purpose of health insurance package is ensure eradication an infectious outbreak of disease, and then such program should also ensure a universal coverage. Taking for example, the case of CHIP through CHIPRA the purpose of the program was to safeguard and prevent the spread of disease among school-going age children. In 2016, an eminent Ghanaian Scholar in the area of Health economics, argued under the concept of epidemiology and the disease control that, in the jumble of low prevalence, disease can be controlled or eradicated at a zero cost (i.e. under full insurance coverage) without any co-payment or fee for service (Adu-Frimpong, 2016). He further postulated that disease can be eradicated in the mix up of epidemic through universal coverage in order to improve upon the health-status of the people (Adu-Frimpong, 2016). Toward this end, it is a fact that Louisiana State has been ranked near to the ground in public health, and still has many confrontation and constraint to health insurance policies as compared to other states in the United States of America. As a result this particular study is to review the CHIPRA by accessing the opinions of the citizens to better inform the policymakers on the need for equality in demand of CHIP through CHIPRA for all children in the State of Louisiana as well as United State as a whole in order to effectively control any outbreak of infectious disease among the school-going age children. 


\section{LITERATURE REVIEW}

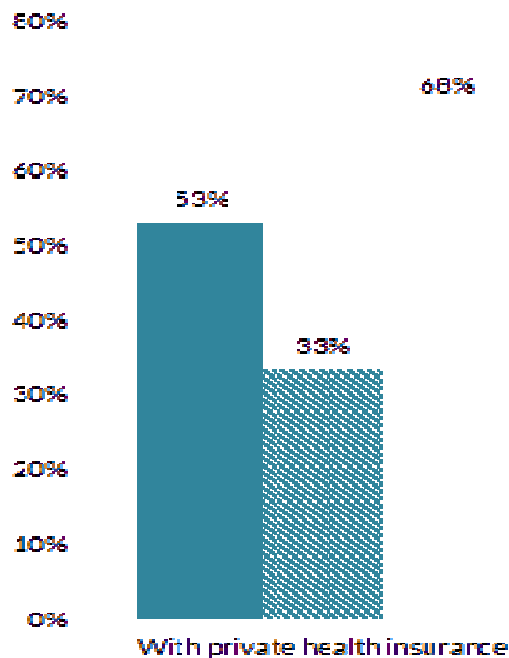

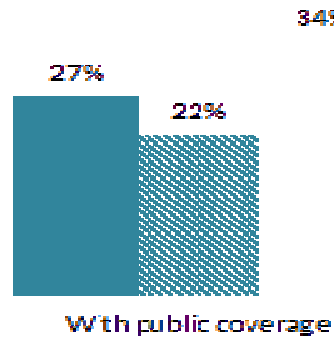

- All immigrarts

Wexican imrigrante

Native barn

Figure 1: Children Insurance Packages and their Subscriptions

Figure 1 reveals the Children Insurance Packages and their corresponding Subscriptions in the United States of America. It is quite obvious from the graph that $68 \%$ of all the Native born have private insurance coverage, while $53 \%$ of all the immigrants born have private insurance coverage and $33 \%$ for Mexican immigrants had private insurance. Again, regarding the public health insurance scheme or coverage, about $34 \%$ of all the Native born have public insurance coverage, while $27 \%$ of all the immigrants born have public insurance coverage. However, $27 \%$ of all the immigrants are left uninsured, while only $9 \%$ of the native born are left uninsured.

Undeniably, migration is as old as history. Human history is associated with migration. As a result of history, United State has been the host of immigrants since 1820 up-to-date. The population of the United State children has also increased overtime due to the increased in the immigrant children from both first generation immigrants (i.e. those who were born outside the United States of America) and Second generation immigrants (those who were born in United States of America). It seems that these immigrants were always at nuisance in the sight of the law, especially for the case of CHIPRA in relation to the issues related to healthcare, employment, educational privileges', and insurance subscriptions. Perceptibly, these legal constrictions expose the vulnerable immigrants to be easily infected with diseases, and sickness, whenever there is an outbreak. According to Adu-Frimpong (2016) under the concept of epidemiology, it very alarming that disease can easily spread, and becomes difficult to control or curb with a positive price of medication, that is without insurance packages or without co-payment or full coverage. Surprisingly, over the past decade, as observed in figure 1, the 10 years annual moving averages data, revealed that the flow of both legal and illegal immigrants has increased consistently thereby fulfilling history. The alarming rising in the total number of immigrant's population has subsequently lead to the tremendous increase in the number of immigrant children across the states in the country (i.e. USA). In spite of the tremendous increase of the immigrant children in the United States of America, CHIP has yet neglected the less nuisance immigrant children who has reached school going age across the country (i.e. USA). 


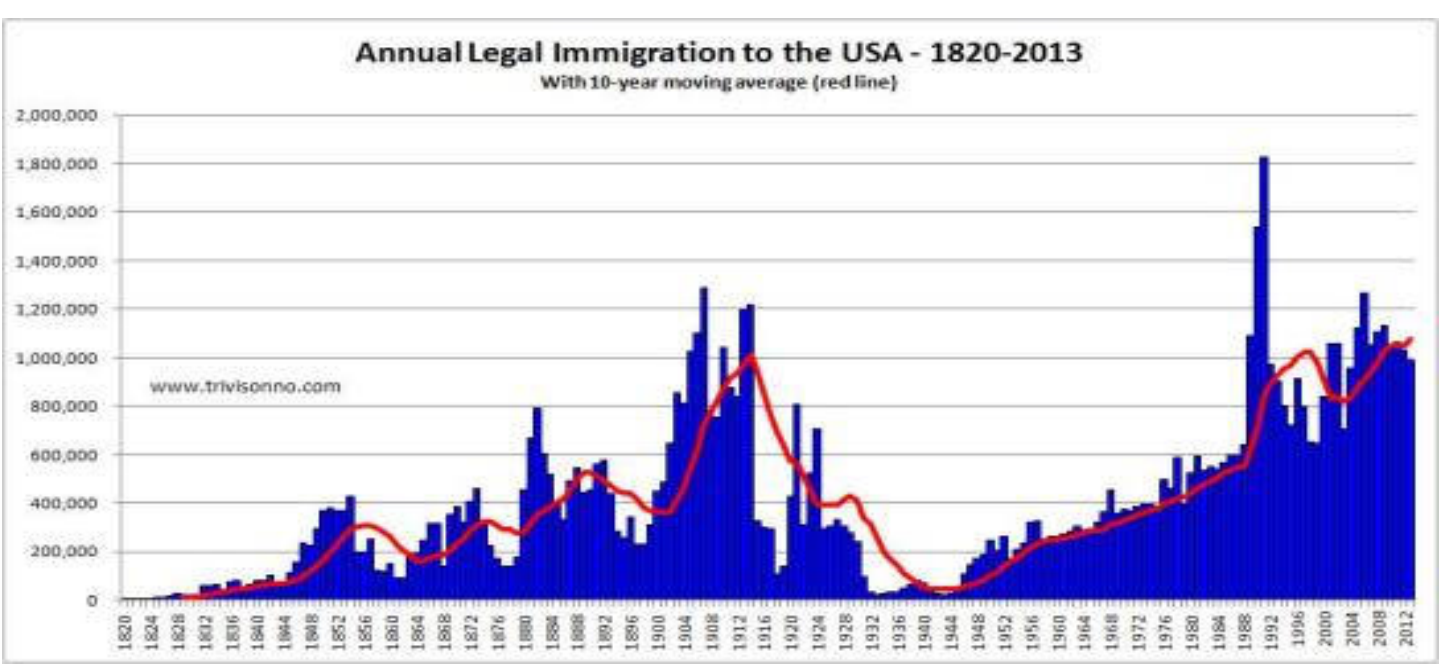

Figure 2: 10 Year- Annual Moving Averages of Legal Immigration Population to USA between 1820 and 2012

\section{THE EPIDEMIOLOGCAL CONCEPT OF THE SPREAD OF DISEASE IN THE UNITED STATE OF AMERICA}

According to Adu-Frimpong (2016) the spread and prevention of diseases has become a major concern to many health experts and organizations across the globe. With specific reference to the Lackland nurses research in San Antonio among camps, it was underlined that four (4) teenagers in their camp were observed to be diagnosed with tuberculosis. According to these nurses, the children or teenagers were really sick, and needed immediate treatments. In fact, David Lakey press (2014) reported that tuberculosis was definitely there and have to be tackled ones and for all. Also, the report revealed that Dr. Marc Siegel, a professor of medicine at New York University's Langone Medical Center and a Fox News Team medical contributor, argued that tuberculosis appears to be spreading through several counties in southern Texas. He further accentuated that tuberculosis and other communicable diseases needs to be carefully monitored and screened for control and prevention. His realistic recommendation is very easy for achievement - but this particular recommendation cannot be possibly prevented or controlled under the current circumstances (no universal coverage), hardship (or poverty) which also serves as a hindrance to affordability, hence the spread of diseases. To reflect on the possibilities of reviewing the CHIPRA and its relevance of CHIP implementation, many researchers have underscored the need for all-inclusive insurance package for every school-going child in order to make disease eradication possible. Furthermore, it has also been observed by the scholars and many policymakers that in the 1950s population density contributed to the rapid spread of diseases, especially among people who live in close propinquity to each other. According to David Lakey (2014) statistically, more than $60 \%$ of the worldwide population lives in urban areas- with more of these people living in dense conditions, thereby causing frequent contact between the people (i.e. constant interaction among susceptible individuals and infected groups), leading to the easy spreading of diseases (Adu-Frimpong, 2016). A typical case is likely to be observed in the United States of America's schools since not all the students are covered with insurance. As a result in the long-run, the susceptible school children who are uninsured due to immigration policy issues will be infected with the diseases whenever they come in contact with the infected individuals who are outside the CHIP program to spread the diseases/illness among the susceptible children making eradication of disease impossible. The hazard rate and prevalence rate of diseases are always high whenever there is no full and universal coverage of insurance (AduFrimpong, 2016). Therefore, in order for the policymakers to control the spread of disease--- they should ensure equal coverage and insurance policy among all students, irrespective of their resident status (i.e. universal coverage). It is as a result this particular study is bringing to the notice of the policymakers, legislative body and governors of the various states the need for CHIPRA review in order to control and prevent diseases (or any outbreak) or any unexpected future healthcare cost.

\section{METHODOLOGY}

The study is exploratory in nature. It is parametric analysis (i.e. hypothesis testing). It utilizes both primary and secondary sources of data. The secondary sources of data were derived from the U.S. Immigration website, U.S and Louisiana Insurance website and some other relevant Journals on Louisiana CHIP. The secondary extant 
data included the period between 1820 and 2012 from the U.S. Immigration website and 2000 -2013 extant data from U. S. Census Bureau, population division. As part of the primary source of data, the study further used stratified random sampling technique to solicit for relevant information regarding the Louisianans perceptions about CHIP, after several years of the program's implementation. The study sought to find out how the population thinks about the CHIP-program in relation to fairness, equity, and resource allocation. A total sample of 650 respondents identified to answer the questionnaires. A large sample was used in order to increase reliability and validity of the findings for the purpose of generalization and forecasting. The study specifically, focused on six (6) selected parishes with Head-Start schools in Louisiana.

\section{Conceptual Model of Chi-Square Goodness of Fit-Test}

The Chi-Square Goodness of Fit-Test model is used to test for a single variance. In addition, the chisquare statistics is used to see whether a frequency distribution fits into a specific pattern. For example, to find out whether there is the need to review or revised CHIPRA across the United States of America, specifically in Louisiana. Perhaps, since the study explores to test to see whether a frequency distribution fits a specific pattern for policy revision to ensure disease eradication among children or not, therefore, the chi-square goodness-of-fit test is used. Before computing the test value for Chi-square goodness of fit test, there is the need to state the hypothesis.

$\mathrm{H}_{0}$ : The need for CHIPRA review is not critical (or significant) to the control and prevention of diseases.

$\mathrm{H}_{1}$ : The need for CHIPRA review is critical (or significant) to the control and prevention of diseases.

\section{Formula for the Chi-Square Goodness-of-Fit Test}

$$
X^{2}=\Sigma \frac{(0-\pi)^{2}}{F}
$$

With degrees of freedom equal to the number of categories minus 1 , and where; $\mathrm{O}=$ observed frequency, and $E$ = expected frequency. Note: Two assumptions are needed for the goodness-of-fit test. These assumptions are given as: (1) The data are obtained from a random sample, and (2) The expected frequency for each category must be 5 or more.

\section{DATA PRESENTATION AND ANALYSIS}

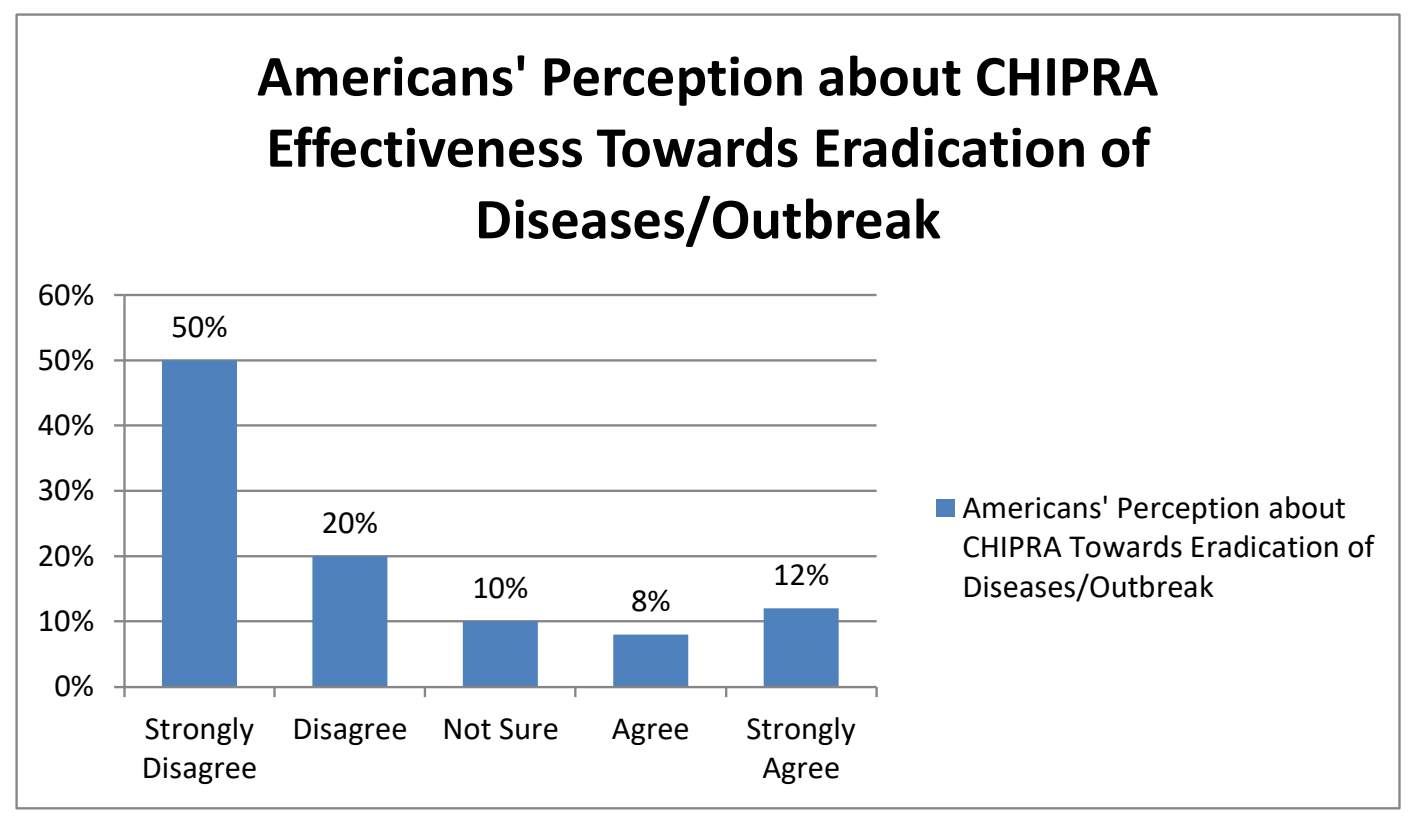

Figure 3: Americans' Perception about CHIPRA towards Eradication of Diseases/Outbreak

Data Source: Field data- August, 2019 
Figure 3 presents the perceptions of the Americans residents of the Baton Rouge community for both natives and immigrants. These respondents were asked to assess the need for the effectiveness of the CHIPRA implementation towards disease eradication. It is quite obvious from the data that about $70 \%$ of the residents of Baton Rouge in Louisiana, USA, who responded to the questionnaires both disagree and strongly disagree- were against the fact that CHIPRA can realize its mission and objective by protecting the children of the native Americans against an outbreak of disease (i.e. they were of the opinion that its policy implementation towards disease eradication is less effective). This particular finding is consistent with the argument of the concept of disease eradication under the theory of epidemiology reviewed and discussed by Adu-Frimpong (2016), in the book titled "the theory and practice of health economics". He argued that it is impossible to eradicate disease under no full insurance coverage whenever there exist a constant interaction between the susceptible individuals and infected individuals within a given environment. On the other hand, $20 \%$ of the residents of Baton Rouge in Louisiana, USA, who responded to the questionnaire both agree and strongly agree to the fact that CHIPRA can realize its mission and objective by protecting the children of the natives Americans against an outbreak of disease regardless of full coverage, while $10 \%$ were not sure of how CHIPRA could assist the country in controlling the spread of diseases due to its current policy (i.e. no universal coverage among children of schoolgoing-age).

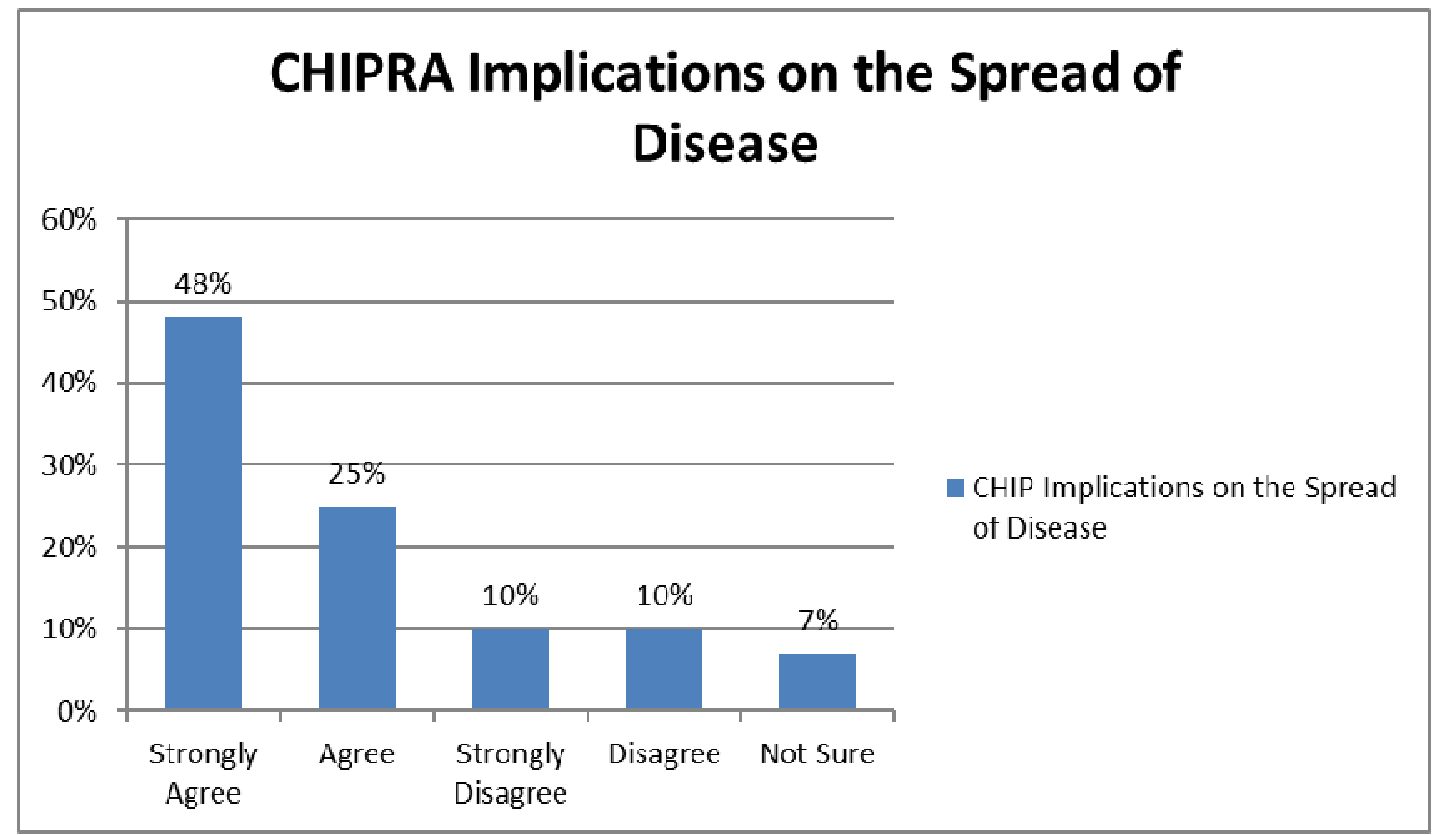

Figure 4: CHIPRA Implications on the Spread of Disease

Data Source: Field Data- August, 2019

Figure 4 discusses about Americans perception of the residents of Baton Rouge for both natives and immigrants-by assessing the implications of the implementation of CHIPRA towards the spread of disease among Americans children. This section reveals the general public perception on the health-risk implications regarding the implementation of CHIPRA on early-child schools, Head starts and the entire education sector across the country. Figure 4 reveals that about $73 \%$ of the residents of Baton Rouge in Louisiana, USA, who responded to the questionnaire both agree and strongly agree to the fact that CHIPRA - in their own opinion the implementation of the ACT through CHIP in the long-run is likely to serve as a secondary source of disease outbreak (or spread of disease). This particular finding is also consistent to the concept of the spread and eradication of diseases under the theory of epidemiology argued by Adu-Frimpong (2016), such that whenever there is no (or absence) of universal coverage of social health insurance, disease spread very quickly. On the other hand, $20 \%$ of residents of Baton Rouge in Louisiana, USA, who responded to the questionnaire both disagree and strongly disagree to the fact that CHIPRA in the long-run, will aid in the spread of diseases, while $7 \%$ of the respondents were not sure of how CHIPRA could contribute to the spread of diseases in the long-run without full health insurance coverage. 


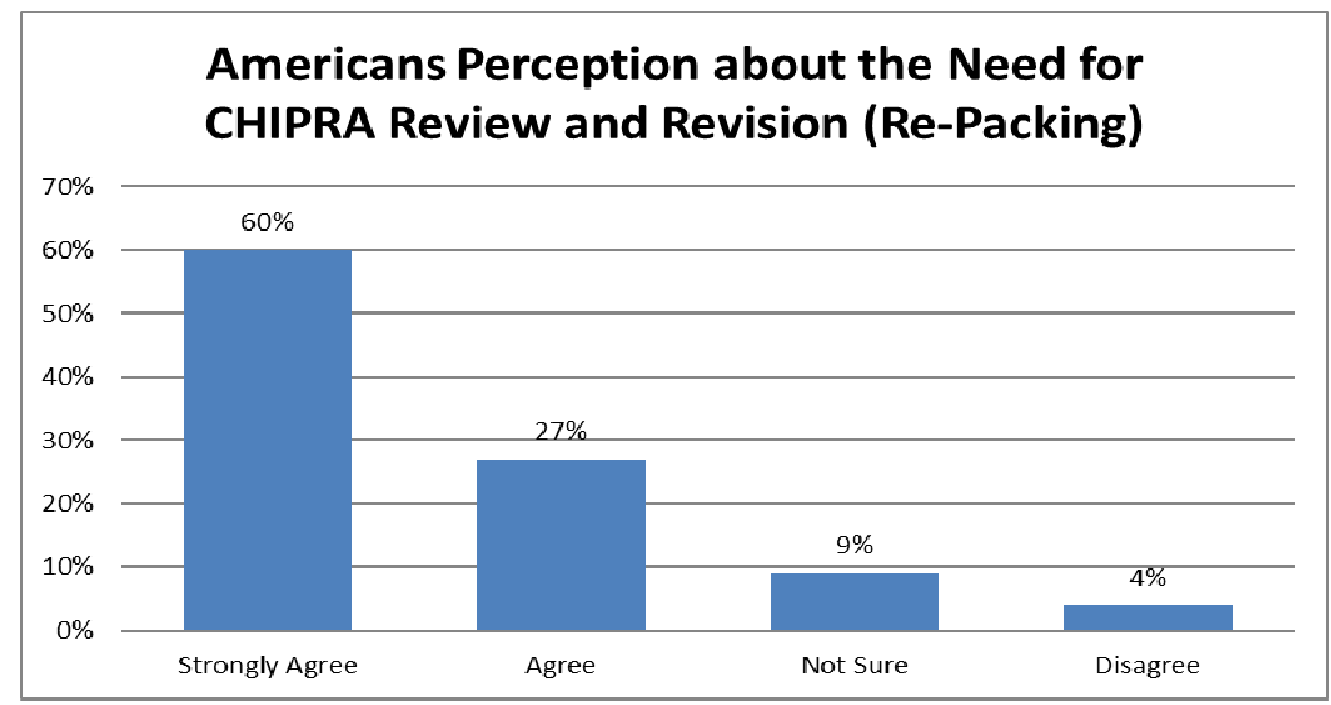

Figure 5: Americans Perception about the Need for CHIPRA Review and Revision

Data Source: Field Data- August, 2019

Figure 5 discusses about the concerns of Americans residenst of Baton Rouge in Louisiana, USA, who responded to the questionnaire regarding the concept of re-packaging of CHIPRA, through an effective policy review and revision for the betterment of the future of country's health in general. It is also apparent from the analyzed data that about $87 \%$ of the residents of Baton Rouge in Louisiana, USA, who responded to the questionnaire both strongly agree and agree to the fact that there is a critical need for the CHIPRA -re-packaging through review and revision in order to include all school-going age children in the country regardless of their immigration status in order to ensure a healthy population. This is consistent with Adu Frimpong (2018) concurrent argument that a healthy nation depends on a healthy workforce (or citizens). They further asserted that the future of every healthy nation depends on the healthy state of the youth (or young population). Conversely, $4 \%$ of the respondents from the residents of Baton Rouge were of the view that CHIPRA is a good policy which does not need any major review and revision, while $9 \%$ of the respondents were not sure whether CHIPRA needs to be reviewed.

Chi-Square Goodness of Fit-Test Estimation for CHIPRA Review on Disease Control and Prevention Given the Chi-Square Critical Value of 9.488 at 4 degrees of freedom $(5-1=4)$ and $\alpha=0.05$. Both the null and alternative hypotheses are given as follows: $\mathrm{H}_{0}$ : The need for CHIPRA review is not critical (or significant) to the control and prevention of diseases. $\mathrm{H}_{1}$ : The need for CHIPRA review is critical (or significant) to the control and prevention of diseases. The data is calculated with the formula given the table below:

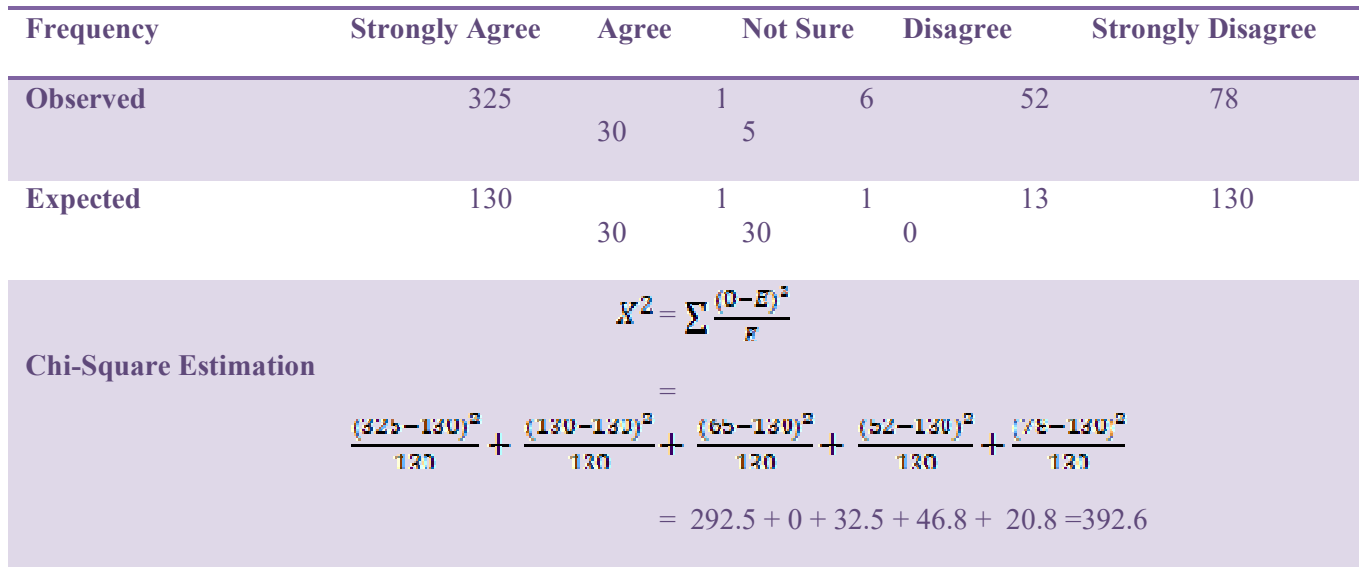

Source of Data: Field Data August, 2019 
The above data reveals the Chi-square Goodness of Fit-Test estimation for the need for CHIPRA review and revision in order to ensure efficient and effective control and prevention of diseases across the country. Based on the result of the data analysis, the researcher has enough evidence to reject the null hypothesis which claims that the need for CHIPRA review is not critical (or significant) to the control and prevention of diseases since the Chi-square estimated value of 392.60 is greater than the Chi-square critical value of 9.488 at $5 \%$ significance level. This implies that the need for the CHIPRA review and revision in order to ensure efficient and effective control and prevention of diseases across the country is very critical to the development of the country. This particular finding is consistent with the assertion by Grossman (2000) and Adu-Frimpong (2016) that a nation's wealth depends on its healthy population. This is because health of a given population is observed to be both a consumption and investment good.

\section{CONCLUSION AND POLICY IMPLICATIONS}

The importance of this particular study is underscored by the fact that health is wealth. Creating a healthy nation is equivalent to creating a wealthy nation. Therefore, this research is helpful to the State of Louisiana as well as the United States of America as a whole to advice the policymakers and also create the awareness of the need for a healthy nation (or a state). Deductively, the study reveals to all stakeholdersincluding governors, policymakers, mayors, senators, congress and all other stakeholders that it is practically impossible for the current CHIPRA to assist the government or the various governors to eradicate diseases in the face of an outbreak of infectious disease among the infants (or children) in the early child schools or head start schools in the State of Louisiana and across the country at large in the absence of full universal coverage. Above all, the study recommends that policymakers, legislative bodies, and the various governors should reconsider the need for CHIPRA review and revision to cover all the school going age children across the country in order to protect the children from an outbreak of diseases- by so doing will ensure a healthy nation in the long-run. The all inclusiveness into the design of CHIPRA will go a long way to minimize future outbreak of diseases, increase the speed for eradication, and improve upon efficiency as well as effectiveness of CHIPRA implementation.

\section{REFERENCES}

Adu Frimpong, A. (2016). Conceptual Knowledge on Health as Consumption and Capital goods: A theoretical review of Michael Grossman (2000) Human Capital Model. Information and Knowledge Management, Vol.6, No.5, ISSN 2224-5758 (Paper) ISSN 2224-896X (Online).

Adu-Frimpong, A. (2016).Health Economics Manuscript titled: "Theory and Practice of Health Economics", IISTE (available online at: https://www.amazon.com/Theory-Practice-Health-EconomicsFirst/dp/1622659775).

Anderson, M., Dobkin, C., and Gross, T. (2012). The effect of health insurance coverage on the use of medical services. American Economic Journal: Economic Policy, 4(1), 1-27.

David Lakey, M.D press report. (2014). Texas Department of State Health Services Commissioner.http:/www.foxnews.com/opinion/2014/07/07/immigration-crisis-tuberculosisspreading-at-camps.html

Jenifer Dorsey. (2016). healthinsurance.org Contributor

Monheit, A. C., Cantor, J. C., DeLia, D., and Belloff, D. (2011). How have state policies to expand dependent coverage affected the health insurance status of young adults?. Health services research, 46(1p2), 251267. 